Résumés des conférences et travaux

\title{
Dialectes et histoire de la langue grecque
}

Jeremy Rau

\section{(2) OpenEdition}

Journals

Édition électronique

URL : https://journals.openedition.org/ashp/2771

DOI : 10.4000/ashp.2771

ISSN : 1969-6310

Éditeur

Publications de l'École Pratique des Hautes Études

\section{Édition imprimée}

Date de publication : 1 septembre 2018

Pagination : 428-430

ISSN : 0766-0677

\section{Référence électronique}

Jeremy Rau, «Dialectes et histoire de la langue grecque », Annuaire de l'École pratique des hautes études (EPHE), Section des sciences historiques et philologiques [En ligne], 149 | 2018, mis en ligne le 11 juillet 2018, consulté le 03 août 2021. URL : http://journals.openedition.org/ashp/2771 ; DOI : https:// doi.org/10.4000/ashp.2771 


\title{
DIALECTES ET HISTOIRE DE LA LANGUE GRECQUE
}

\author{
Conférences de M. Jeremy RaU, \\ université Harvard (États-Unis), \\ directeur d'études invité
}

Un des traits les plus remarquables de la Grèce antique est le degré extraordinaire de la diversité dialectale qui est attestée pour la langue grecque, telle qu'elle était parlée en Grèce, en Asie Mineure, dans la mer Égée, et plus largement dans la mer Méditerranée. Bien que l'attique, le dialecte d'Athènes et du territoire environnant, soit la forme la plus connue et probablement la mieux documentée du grec ancien, chaque région de la Grèce et de l'aire linguistique grecque avait sa propre variété dialectale : certaines de ces variétés étaient relativement proches du dialecte attique, alors que d'autres étaient radicalement différentes. Cette diversité dialectale, qui est bien représentée dans les sources épigraphiques et littéraires dont nous disposons, s'étend des premiers documents attestés de la Grèce mycénienne, $c a$ 1650-1200 avant notre ère, en passant par les périodes archaïque et classique, ca 800-323 avant notre ère, jusqu'au début des royaumes hellénistiques, vers 323 avant notre ère, stade où elle cède la place finalement à un dialecte transrégional appelé koinè, i.e. « [langue] commune ». L'histoire de ces dialectes occupe une place particulièrement importante dans les études de philologie sur la Grèce ancienne, pour deux raisons : d'une part, les dialectes ont joué un rôle significatif dans l'histoire et la culture grecques, et d'autre part, leur étude dans le cadre de la linguistique historique a fourni aux chercheurs un outil inestimable pour retrouver des aspects autrement inaccessibles de l'histoire et de la préhistoire du monde grec, en sorte qu'elle s'est développée très largement en vue de la reconstruction historique et culturelle de la Grèce ancienne.

Malgré l'importance qui est reconnue à l'histoire des dialectes du grec ancien, il n'existe pas encore de description linguistique qui réponde de façon complète et définitive aux questions suivantes : quelle fut la période de l'émergence de ces dialectes, quelles innovations eurent un rôle décisif dans leur formation, et comment ils se sont ensuite développés. Des avancées récentes en archéologie et en paléographie mycéniennes offrent une voie d'entrée d'une grande importance dans cette perspective : en effet, elles ont révélé que certains des dépôts des textes en linéaire B qui nous sont connus remontent globalement à deux cents ans plus tôt que la date qui avait été admise depuis longtemps. Le but de ces conférences est d'utiliser ces résultats, ainsi que d'autres développements nouveaux en linguistique grecque pour établir l'histoire linguistique des dialectes du grec ancien depuis leurs débuts jusqu'à la moitié du $\mathrm{I}^{\mathrm{er}}$ millénaire avant notre ère.

\section{Les dialectes grecs : filiation, diffusion et convergence}

La première conférence est consacrée à la filiation génétique du grec ancien à partir de son lointain ancêtre linguistique, le proto-indo-européen, jusqu'aux $\mathrm{II}^{\mathrm{e}}$ et 
$\mathrm{I}^{\mathrm{er}}$ millénaires avant notre ère. Elle situe le grec ancien par rapport aux langues les plus proches dans la famille linguistique indo-européenne, elle expose les innovations linguistiques qui sont apparues, elle détermine la chronologie relative d'apparition de ces innovations, et les met en relation avec une datation absolue, à travers leur apparition en mycénien et dans les dialectes du $\mathrm{I}^{\mathrm{er}}$ millénaire. Sur cette base, il est proposé d'établir la répartition dialectale générale en quatre groupes, telle qu'elle a été admise traditionnellement, et correctement, comme il est confirmé : 1) achéen (arcadien, chypriote et mycénien), 2) ionien-attique (attique, ionien oriental, central et occidental), 3) éolien (lesbien, thessalien et béotien), 4) grec occidental (parlers du Nord-Ouest, laconien, messénien, etc.). La conférence analyse aussi la diffusion des innovations linguistiques par-dessus les frontières dialectales du grec ancien, un phénomène connu sous le terme de convergence linguistique, laquelle a affecté le grec ancien à tous les stades de son développement, et qui s'observe non seulement dans des dialectes voisins, mais aussi entre des dialectes d'affiliations génétiques différentes, sur toute l'étendue de la vaste aire géographique qui couvre la Grèce, l'Égée et l'Asie Mineure.

\section{Les dialectes grecs au II millénaire: phonologie et répartition en groupes}

La deuxième conférence retrace la situation dialectale de la Grèce ancienne durant la période mycénienne, ca 1650-1200 avant notre ère. Des découvertes récentes en archéologie mycénienne et dans la paléographie du linéaire B ont prouvé que son emploi couvrait la période 1420-1190 avant notre ère. Elles ont permis de déterminer l'ancienneté relative des différents dépôts de textes qui nous sont connus. Grâce à ces développements philologiques importants, la distribution des innovations phonologiques significatives du point de vue dialectal dans le corpus mycénien est révisée. Il est montré d'après ces innovations que le grec ancien s'était déjà différencié, dès la phase la plus ancienne des matériaux textuels du mycénien, selon les quatre groupes connus globalement au I ${ }^{\text {er }}$ millénaire : achéen, ionien-attique, éolien et grec occidental. On établit que l'achéen, le sous-groupe qui inclut le mycénien, et l'ionien-attique, l'ancêtre de l'attique et des dialectes ioniens, bien que génétiquement distincts, avaient déjà subi une période de convergence linguistique préhistorique, probablement vers le milieu du $\mathrm{II}^{\mathrm{e}}$ millénaire avant notre ère, et qu'ils étaient vraisemblablement voisins sur le plan géographique durant cette période.

\section{Les dialectes grecs au II millénaire : morphologie et répartition en groupes}

La troisième conférence envisage la distribution des innovations linguistiques de l'époque pré-mycénienne dans les quatre groupements dialectaux du grec ancien. Elle retrace le processus de différenciation dialectale préhistorique qui s'est produit au début du $\mathrm{II}^{\mathrm{e}}$ millénaire avant notre ère. En prenant en compte des développements récents dans l'interprétation de la morphologie verbale indo-européenne, elle se concentre sur l'évolution d'une catégorie innovante de verbes contractes, les verba 
vocalia, en achéen et en éolien, où ce type de verbes a subi une série d'innovations analogiques qui ne sont pas triviales. La conférence met ces innovations en relation avec des évolutions phonologiques similaires en achéen et en éolien. Elle se propose de démontrer que ces deux groupes dialectaux descendent d'un ancêtre génétique commun, et que les quatre groupements attestés depuis le milieu du $\mathrm{II}^{\mathrm{e}}$ millénaire ont résulté de la différenciation de deux - ou éventuellement trois, - ancêtres du début du II ${ }^{\mathrm{e}}$ millénaire, le premier ayant donné naissance à l'achéen et à l'éolien, et un second dont proviennent vraisemblablement l'attique et le grec occidental.

\section{Archaïsme, innovation et dialectologie dans la langue homérique}

La quatrième conférence explore la constitution dialectale de la langue homérique. On présente les deux modèles différents, par phases ou par diffusion, de l'association de l'éolien et de l'ionien dans la tradition épique. On prend appui sur la compréhension affinée de la chronologie absolue et relative des innovations linguistiques intervenues en ionien-attique, telles qu'elles ont été retracées dans les conférences précédentes, pour rechercher comment les poètes de la tradition orale de l'épopée homérique ont réagi à l'innovation linguistique propre au néo-ionien, sur deux plans à la fois : comment ils ont adapté le matériau archaïque hérité de la langue formulaire pour le conformer à ses équivalents néo-ioniens, et comment ils ont intégré le matériau linguistique innovant du néo-ionien dans leur répertoire poétique. Cette conférence traite aussi la relation étroite entre l'innovation linguistique du néo-ionien et le matériau dialectal éolien dans la langue homérique. Ce point est illustré spécifiquement par discussion de la lecture Aiveí $\omega<0>$ conservée par Zénodote (en E 263, 323), contre la lecture Aiveíao de l'ensemble de la tradition, pour le génitif singulier du nom propre hom. Aivcías (att. Aivéas), bien attesté dans l'Iliade. 